\title{
THE WATER-BINDING OF THE RETINA
}

\author{
BY
}

\author{
J. A. van Heuven and F. P. Fischer
}

(FROM THE UNIVERSITY OPHTHALMIC CIINIC, UTRECHT)

If one lays a freshly prepared retina in a weak acid solution, the retina at once becomes opaque and thicker. If one lays a fresh retina in a strong, concentrated sugar or magnesium solution the retina immediately becomes more transparent and thinner. The retina that has become opaque and thicker gets heavier; the transparent and thinner one gets lighter. Having become more opaque and heavier in acids, the retina can again be made more transparent and lighter in solutions of sugar. Consequently the described processes are reversible.

This process of alteration of transparency, thickness and weight can be produced in many ways. It happens not only in dead eyes but also in living ones, the above mentioned capacities of the retina can be brought about in living eyes by injections of solutions which promote the water-absorption of the tissues. As far as we know no attention has as yet been paid to such processes in the retina, indeed, researches on the relations of the retina to the water-percentage of the eye are not mentioned in ophthalmological literature. Up to now the retina has been investigated pathologico-anatomically and chemically; physico-chemical and colloido-chemical investigations, however, have not yet been performed. In the following explanation we have tried to make an analysis of the physico-chemical action of the retina especially of its water-binding properties. In this we have followed the method of one of us, because this mode of working proved to be very satisfactory for the analysis of the water-binding of the cornea, sclera, lens and choroid. ${ }^{1}$

It was of course necessary first of all to find out and try the methods which agree with the nature of the retina, before experimental estimations could be made. If one wants to research on the water-binding of colloids one must make measurements of the capacity, the intensity and the form of the water-binding.

The capacity of the water-binding means the extent of the faculty to absorb and to hold water under certain circumstances. A measure of the capacity is the quantity of water which can be absorbed and held under these circumstances. The capacity depends on the condition of the water-percentage, the grade of dispersion, the by-mixtures, the temperature and the duration of the experiments. It is easy to keep temperature and time constant and to ascertain the water-percentage on small samples. The quantity of water absorbed can be established by weighing. The 
conditions of the experiments are given by the liquids in which the retinae have been laid.

The intensity of the water-binding means the extent of the power to absorb and to retain water under given circumstances. A measure of the intensity is the rapidity of the absorption of water, e.g., the extent of the facility with which water is absorbed. The intensity depends on the same factors as the capacity, but as to the process of the water-binding only the intensity is essential. The rapidity of the absorption and the loosening of water can again be ascertained by weighing and by the extent of the capacity with which water is held, if the retina is laid in solutions of a known capacity to attract water.

The form of the water-binding means the nature of the powers which promote the absorption of water. Water can be absorbed and retained as hydrate-water for instance, and certainly hydratewater plays a great part in the large hydration-capacity of albumen.

Generally it is only loosely bound and consequently easy to remove. More fixed is the capillary-bound water, which is found in the holes of colloidal dimensions. It is difficult to remove, because it obeys capillary laws. Still more firm is the absorptionwater fixed by the energy-field of the surfaces. Finally water is also held by the by-mixtures which attract it osmotically. Especially significant is, however, the water which is stored in and round the parts of the substance divided into colloids which is held as colloid-bound water. It is very difficult to ascertain the form of the water-binding in detail, often it is not ascertainable. Yet we can always find out which form prevails. Further it appears from the reaction in measuring the capacity, whether the examined substance absorbs water according to the rules of swelling or in another way, which in itself allows suggestions as to the form of the water-binding. By the already mentioned researches of one of us we can compare the water-binding of the retina with that of other tissues of the eye, and consequently we are able to give a complete notion of the water-binding conditions of the eye. We hope to be able to point out that such researches are not only scientifically important, but that they are also able to explain and to reveal important clinical connections. We have gained the experience that objections are made to the effect that in researches on tissues like these on which we have experimented, it would be impossible to consider so complicated a tissue as the retina from one point of view, for instance the colloido-chemical one.

We think that the result of our experiments is the best answer to such objections. It is shown that notwithstanding its complicated structure the retina behaves indeed as substances like gelatine, consequently from the point of view of the colloid-theory 
it is well defined and can be classified. We shall begin by describing our method of preparation. After this we will describe the measurement of the capacity, and then that of the intensity. Finally we shall explain the form of the water-binding of the retina and in each section we will compare the results with those of the other tissues of the eye. We have performed our studies with ox eyes obtained as fresh as possible from the slaughter house. The eyes were bisected equatorially and the vitreous body of the eye was removed by capsizing the hind half of the globe. Now the retina was exposed and was separated with a china spatula, seized by a broad pincette, and pieces, in proportion as they were wanted, were cut off. These were laid in little baskets, made of copper (messing), which were standing on a tripod in a weighing glass of a known weight. The weighing glass was closed with a lid and weighed. As the weight of the weighing-glass together with the basket and the tripod was known, the weight of the piece of the retina was made evident. The baskets were cylinder-shaped and were perforated on all sides with holes of a diameter of $0.5 \mathrm{~mm}$. In preliminary researches we had ascertained that in water or in other liquids of which we intended to make use, the baskets did not change their weights within a period of two hours. When the retina had been weighed in such a basket in a weighing glass, the basket with the retina was taken out of the weighing-glass with a pincette, it was put into the testing-solution, which covered the basket and its contents, and after a definite period was taken out again in the same way, finally it was put on English blotting paper, so that the water could be removed from the basket without affecting the contents.

Any liquid that did not trickle down by itself was cautiously removed by being carefully wiped with blotting paper. After this the basket was again put into the weighing-glass and the latter was weighed. From the difference of the weight we could calculate the absorption or the loss of water in percentages. If distilled water had been used as immersion-liquid, an increase in weight could only be caused by an absorption of water. When there was a loss of weight other substances could still have been dissolved besides the water. For that reason we have taken the trouble to ascertain in preliminary researches which substances from the retina dissolve in the immersion-liquid within two hours. We found that hardly anything dissolved in the first hour, that after two hours, however, a definite loss of weight appeared. The consequence of this was, that we decided not to extend our researches over a period of more than one hour. Such simple conditions exist only when water is the immersion-liquid. From all other liquids, substances, which have been dissolved at the same time, are absorbed by the retina, but also set free again. In 
proportion to the exchanged quantity of water the exchange of dissolved substances is however so small, that this circumstance cannot be considered as a source of error. We have nevertheless taken this factor into aocount and we have always examined the immersion-liquid after finishing our experiments. We found its composition always constant within the limits of experimental error. We have always used such quantities of the immersionliquid that these were at least 100 times the volume of the basket filled with retina. The temperature was about the same with all experiments, namely indoor temperature varying from $60^{\circ}-70^{\circ} \mathrm{F}$. Before we went on with the proper measurings of the capacity of the water-binding, we ascertained the water-percentage of the

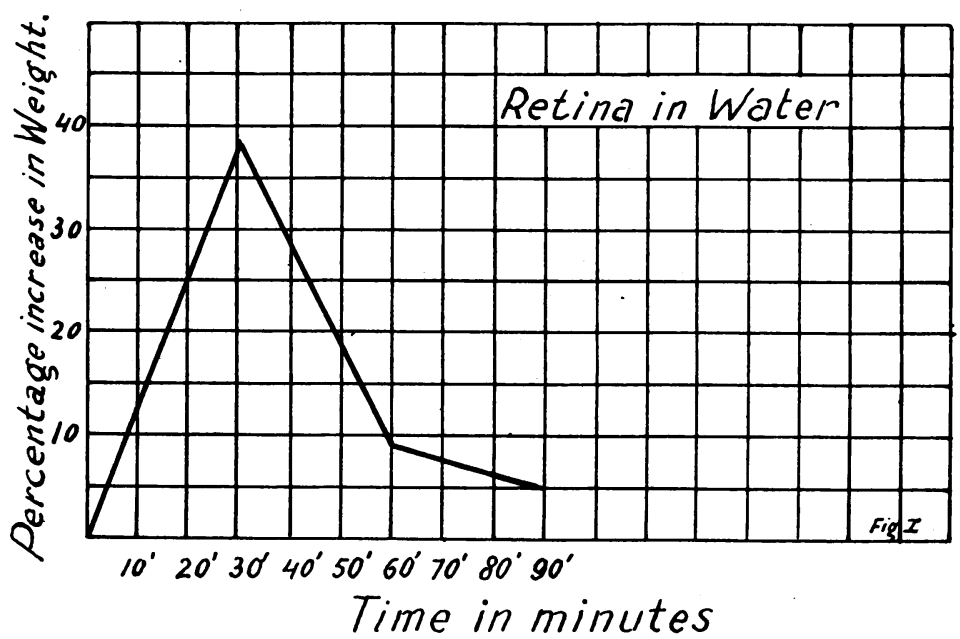

retina by drying it to its constant weight. We found a waterpercentage of about 88-89 per cent. After this we ascertained the water-absorption out of pure water. In Fig. 1 it is shown that in the first 30 minutes of its stay in distilled water the retina increases its weight by 36 per cent. of its initial weight, then the increase in weight decreases again to 8 per cent. of the initial weight, measured after an hour. After 90 minutes it is only 5 per cent. more than its initial weight. It is obvious that the result of this experiment shows that the further series of experiments have to be limited to an immersion-time of half an hour, because after half an hour the increase in weight is largest. Fig. 1 is the result of numerous separate experiments and it shows average values with very small differences. As we intended to examine the water-binding in acids and alkalies, we have first examined the absorption of water in solutions of different hydrogen-ionconcentration. For this purpose we made a series of buffer-solutions with known $\mathrm{P} h$. We used the standard-solutions of 
Sörensen and the veronal buffer of Michaelis; into these solutions the retinae were brought in the way described above and after an interval of half an hour the change in weight was measured. The presence of the retina did not cause any change in the $\mathrm{Ph}$ of the solutions.

The result of these tests is shown by schedule I.

SCHEDULE I.

\begin{tabular}{c|c}
\hline Ph & $\begin{array}{c}\text { Increase in weight, } \\
\text { in \% }\end{array}$ \\
\hline 8.0 & +14 \\
7.5 & +14 \\
6.9 & +13 \\
5.9 & +15 \\
4.9 & +13 \\
4.5 & +12 \\
3.5 & +13 \\
2.6 & +14 \\
\hline
\end{tabular}

Considering the result of these experiments we can say, that this hydrogen-ion-concentration has no influence on the absorption of water. There is no need to take into consideration differences of 3 per cent. Compared with the water-absorption from pure water a decrease of the water-absorption showed itself in these experiments. This decrease cannot be attributed to the $\mathrm{P} h$ of the solutions, because these buffering-solutions are saltsolutions. There may also be the question of a specific saltreaction. This will be taken into consideration afterwards, when we shall discuss the reaction of salt on the absorption of water. We have continued our endeavours with experiments about the water-absorption from acids. We used three mineral acids and three organic acids and each of them in the concentrations shown in schedule II.

SCHEDULE II.

\begin{tabular}{|c|c|c|c|c|c|}
\hline & & m & $\mathrm{m} / 10$ & $\mathrm{~m} / 100$ & $\mathrm{~m} / 1000$ \\
\hline Hydrochloric acid & $\ldots$ & -51 & -13 & -0 & +15 \\
\hline Sulphuric acid ... & $\ldots$ & -36 & -28 & -6 & +14 \\
\hline Phosphoric acid & $\therefore$ & -16 & -0 & -23 & +110 \\
\hline Acetic acid & $\ldots$ & -36 & -27 & -21 & -1 \\
\hline Lactic acid $\quad \ldots$ & $\ldots$ & -30 & -14 & -5 & +10 \\
\hline Citric acid & $\ldots$ & -17 & -13 & -6 & +4 \\
\hline
\end{tabular}


From schedule II it appears distinctly that in equinormal acids the retina absorbs quite different quantities of water. It is not to be doubted that, generally speaking, the concentration of acids is of essential significance; when the concentration decreases the water-absorption increases. In stronger concentrations we observe an extraction of water, in weaker ones even a real absorption of water. If we compare the water-absorption from pure water with that from acids, we find that both in strong as well as in weak solutions of acids the water-absorption is checked and that this checking is accordingly larger in higher concentrations of the acid. Schedule II shows, moreover, that each acid possesses its own characteristic influence on the water-absorption, which is most pronounced with phosphoric acid. Phosphoric acid is the only acid which may be compared with pure water considering its water-absorption. We thought this fact important, because it is known from the researches of Lange and Simon ${ }^{2}$ that the acid which is liberated from the retina by the action of the light is phosphoric acid. After this we proceeded to experiments with alkalis. Results of our measurings are found in schedule III.

In this schedule are many empty places. These indicate that measurings were impossible in these alkalies and these concentrations, because the retina was swollen and changed so much, that weighing appeared to be impossible. It was especially striking that the retina became quite transparent in these alkalies and concentrations, so that it could hardly be found in the liquids and when removing it, one obtained very long threads. These threads were as clear as water, they did not show any non-homogeneous qualities as are to be found, for instance, in glassthreads, which show rosary-like thickenings or look like a fine string of pearls. When being dried they become solid and scarcely distinguishable from cobwebs. We have also examined such threads histologically, but we found nothing, they do not consist of elements of the retina, but of the alkali combined with a substance from the retina. It is also possible to produce such threads from other tissues of the eyes by putting the latter in alkalis, but the threads from the uvea are of a different nature. A short time ago one of us pointed out the clinical importance of this phenomenon.

SCHEDULE III.

\begin{tabular}{l|c|c|c|c}
\hline & $\mathrm{m}$ & $\mathrm{m} / 10$ & $\mathrm{~m} / 100$ & $\mathrm{~m} / 1000$ \\
\hline Hydroxide of sodium ... & - & - & - & - \\
$\begin{array}{l}\text { Hydroxide of potassium } \\
\text { Hydroxide of ammonium }\end{array}$ & - & - & +40 & +32 \\
Hydroxide of calcium ... & - & +107 & -45 & -18 \\
\end{tabular}


It is evident from schedule III, that equinormal alkalis have a different influence on the water-absorption. Further it is shown that the more concentrated the alkali, the larger is the waterabsorption; except in the hydroxide of calcium* in which the proportions are the reverse.

Compared with the water-absorption from pure water, alkalies promote water-absorption and do this in rising concentrations. They act in a way opposite to the acids.

Further it follows from schedule III that the hydroxide of sodium promotes water-absorption mostly, next are hydroxide of potassium and hydroxide of ammonium. In order to carry out a comparison between acids and alkalies of the same $\mathrm{H}$-ions, respectively the same $\mathrm{OH}$-ion-concentration, we have made experiments with $\mathrm{n} / 50$ muriatic acid, phosphoric acid, hydroxides of sodium and potassium. It appeared that in these concentrations the water-absorption was high in a quite different manner, so that we may say that the water-absorption cannot be simply dependent on the $\mathrm{H}$ - and $\mathrm{OH}$ - concentration respectively. If the waterabsorption in isonormal alkalies and acids is different in comparison with that from pure water, the water-absorption can hardly be explained otherwise than by swelling-processes. This supposition becomes absolute evidence, when it can be shown that the water-absorption obeys a law in the sense of the series of Hofmeister. Hofmeister ${ }^{3}$ has proved with gelatine plates, that in comparison with the water-absorption from pure water these plates undergo a checking in equimolar salt solutions of increasing concentrations. This checking is characteristic of each particular salt. We started from such ion-series of Hofmeister and we studied the water-absorption of the retina therein. In one tested series we varied the kations, in a second the anions. In the kation series we used chlorides, in the anion series sodium salts. We have tested the kation series in neutral, acid and alkaline reactions. To obtain acid and alkaline salt solutions of the same molarity and to retain at the same time a definite normality of the acids and alkalis we acted as follows : $-30 \mathrm{c.cm} .2 \mathrm{~m} . \mathrm{NaC} 1+30 \mathrm{c.cm} . \mathrm{n} / 5$ $\mathrm{HCl}+0$ c.cm. $\mathrm{H}_{2} 0=\mathrm{m}$. $\mathrm{NaCl}+\mathrm{n} / 10 \mathrm{HCl} 0.60$ c.cm. 6 c.cm. $\mathrm{m} \mathrm{NaC} 1+30$ c.cm. n/5 $\mathrm{HC} 1+18$ c.cm. $\mathrm{H}_{\diamond} 0=10 \mathrm{NaC} 1+\mathrm{n} / 10$ $\mathrm{HCl} 0.60 \mathrm{c.cm}$. By changing the molarity of the salt, when the proportion of the quantities was the same, we produced all the necessary salt solutions after this precept. In schedule IV the results of the kation experiments have been collected.

In this schedule we mean by " $n$ " the water-absorption in percentages when the reaction is neutral, by " $s$ " when it is an acid reaction, by " $a$ " when it is an alkaline one. Consequently the

\footnotetext{
Hydroxide of calcium can only be made as $n / 30$, that is why we only used it as
$n / 100$ and $n / 10 c 0$.
} 
influence of concentration and reaction can be clearly ascertained in this schedule. Magnesium and calcium-chloride precipitate when the reaction is alkaline, for that reason the water-absorption in these solutions could only be measured when the reaction was neutral or acid.

SChEdUle IV.

\begin{tabular}{l|c|c|c|c|c|c|c|c|c|c|c|c|c}
\hline & & \multicolumn{3}{c}{$\mathrm{m}$} & \multicolumn{2}{c}{$\mathrm{m} / 10$} & \multicolumn{2}{c}{$\mathrm{m} / 100$} & \multicolumn{2}{c}{$\mathrm{m} / 1000$} \\
\hline & & $\mathrm{n}$ & $\mathrm{s}$ & $\mathrm{a}$ & $\mathrm{n}$ & $\mathrm{s}$ & $\mathrm{a}$ & $\mathrm{n}$ & $\mathrm{s}$ & $\mathrm{a}$ & $\mathrm{n}$ & $\mathrm{s}$ & $\mathrm{a}$ \\
\hline $\mathrm{NaCl}$ & $\ldots$ & +16 & -56 & -26 & -8 & -7 & -6 & +9 & -5 & +10 & +48 & -2 & +46 \\
$\mathrm{KCl}$ & $\ldots$ & -36 & -50 & -10 & -20 & -21 & -1 & +9 & -7 & +15 & +29 & -5 & +37 \\
$\mathrm{NH}_{4} \mathrm{Cl}$ & $\ldots$ & -15 & -27 & +6 & +3 & -11 & +36 & +5 & -10 & +50 & +6 & -3 & +52 \\
$\mathrm{MgCl}_{2}$ & $\ldots$ & -30 & -14 & - & -20 & -12 & - & +5 & -8 & - & +28 & -6 & - \\
$\mathrm{CaCl}_{2}$ & $\ldots$ & -40 & -18 & - & -12 & -6 & - & +19 & +6 & - & +85 & +12 & - \\
\hline
\end{tabular}

It clearly appears from schedule IV that when the concentration declines, the water-absorption rises, in comparison with the waterabsorption from pure water it is checked, only in the weakest concentrations the water value is attained. An acid-reaction checks the water-absorption from salt solutions, an alkaline reaction promotes it. Equimolar solutions do not act in the same way. The results of our experiments with an anion series are shown in schedule V.

Schedule V.

\begin{tabular}{lll|l|l|l|l}
\hline & & & $\mathrm{m}$ & $\mathrm{m} / 10$ & $\mathrm{~m} / 100$ & $\mathrm{~m} / 1000$ \\
\hline Na-cyanide & $\ldots$ & $\ldots$ & +76 & +70 & +48 & +36 \\
Na-rhodanide & $\ldots$ & $\ldots$ & +45 & +32 & +11 & +8 \\
Na-nitrate & $\ldots$ & $\ldots$ & +30 & +22 & +32 & +42 \\
Na-acetate & $\ldots$ & $\ldots$ & -8 & +2 & +9 & +20 \\
Na-iodide & $\ldots$ & $\ldots$ & +75 & +48 & +40 & +19 \\
Na-chloride & $\ldots$ & $\ldots$ & -16 & -8 & -9 & +49 \\
Na-bromide & $\ldots$ & $\ldots$ & +105 & +53 & +36 & +20 \\
Na-phosphate & $\ldots$ & $\ldots$ & +115 & +48 & +0 & +8 \\
Na-tartrate & $\ldots$ & $\ldots$ & +16 & +22 & +32 & +46 \\
Na-sulphate & $\ldots$ & $\ldots$ & +5 & +12 & +36 & +60 \\
Na-citrate & $\ldots$ & $\ldots$ & -13 & -1 & +18 & +43 \\
\hline
\end{tabular}

It is perfectly evident from schedule $\mathrm{V}$, that equimolar solutions of natrium-salts exercise a quite different influence on the waterabsorption. Taking cyanide, rhodanide, iodide, bromide and phosphate the water-absorption increases, when the concentration 
of the salt rises, and indeed in comparison with pure water above the water value; taking nitrate, chloride, acetate, tartrate, sulphate and citrate it decreases when the concentration of the salt rises. The water value is attained in the weakest solutions. The first group promotes the water-absorption, the second checks it.

Hofmeister has already made this observation in swelling gelatine-plates and he arranged the anions in a series according to the decrease of the checking of the swelling. His series is not exactly in conformity with the one for the retina, which is not surprising, as retina represents a substance quite different from gelatine. However the same regularity is found in the retina as in gelatine. Salts exercise an influence on the absorption of water which is characteristic for each of them, and is especially manifested in the case of equimolar solutions. Thus the water-absorption of the retina shows itself as a genuine swelling. That appears also from the investigation of anelectrolytes, as is shown by schedule VI.

Schedule Vi.

\begin{tabular}{lll|l|l|l|l|l}
\hline & & $\mathrm{m} / 2$ & $\mathrm{~m} / 4$ & $\mathrm{~m} / 8$ & $\mathrm{~m} / 16$ & $\mathrm{~m} / 32$ \\
\hline Saccharose & $\ldots$ & $\ldots$ & -10 & +18 & +19 & +17 & +15 \\
Glucose & $\ldots$ & $\ldots$ & -20 & +12 & +14 & +15 & +20 \\
Urea $\ldots$ & $\ldots$ & $\ldots$ & +63 & +50 & +42 & +27 & +28 \\
Glycerine & $\ldots$ & $\ldots$ & +60 & +50 & +45 & +47 & +49 \\
\hline
\end{tabular}

As to the anelectrolytes two groups again can be distinguished, one which promotes the swelling, urea and glycerine, in which the water-absorption increases when the concentration rises, although not very evenly, and one which checks the swelling, saccharose and glucose, in which the water-absorption decreases when the concentration rises. Let us now summarise what we have established hitherto. In water the retina absorbs about 40 per cent. water in half an hour. In acids, except in phosphoric acids, the absorption of water is very strongly checked within this time, this depending on the concentration of the acids, the influence of equinormal acids is variable however. The water-absorption is promoted by alkalis, this again depends on the concentration. Equinormal alkalis too have various influences. In equally dissociated acids and alkalis the water-absorption is different, which in accordance with experiments in which the $\mathrm{Ph}$ of the solutions was varied, shows that the $\mathrm{H}$ and $\mathrm{OH}$ concentration respectively is of no fundamental importance to the water-absorption. Salts generally check the water-absorption then depending on concentration. Equimolar sallt-solutions again have various influences. Consequently for water-absorption a series in the sense 
of Hofmeister ion-series, can be composed. Anelectrolytes influenced the water-absorption of the retina in the same way. Consequently the retina must be considered as having the property of swelling, as the described way of water-absorption cannot be brought about in another manner than by swellingprocesses and so the retina must be looked upon as a gel.

The Capacity of the water-binding was measured by the above described experiments. It appeared that the retina is able to achieve more than 100 per cent. of its initial weight through waterabsorption in the sense of swelling. A comparison with the other tissues of the eye shows that the capacity of the water-binding of the retina is somewhat greater than that of the lens, much smaller than that of the uvea, the parts of which, the iris, the ciliary body and the choroid, can increase in weight up to 500 per cent. of the initial weight in alkalis, and considerably smaller than the capacity of the walls of the eye, the cornea and the sclera, which gain in weight up to 2300 per cent. in acids. Only the last mentioned swell more strongly in acids, whilst the inner tissues of the eye swell more strongly in alkalies. We think this fact to be very important.

In order to measure the Intensity of the water-binding of the retina we investigated the time necessary for the swelling, the change of density in swelling, and the swiftness of the secretion of water, in the same way as we did in the cornea, the sclera, the lens and the uvea. In order to measure the swiftness of the waterabsorption we laid pieces of retina, which were prepared in the way described above, in stronger concentrated solutions of anelectrolytes, of which the high osmotic capacity to attract water is well known, and after a fixed time had passed, we ascertained the changes of the initial weight. As the first testing substance we used pyridin. Schedule VII shows the result of these experiments.

Schedule VII.-Pyridin Concentration.

\begin{tabular}{|c|c|c|c|c|c|c|c|c|}
\hline \multicolumn{4}{|c|}{ Time } & $10 \%$ & $20 \%$ & $30 \%$ & $40 \%$ & $50 \%$ \\
\hline $1^{\prime}$ & $\ldots$ & $\ldots$ & $\ldots$ & -20 & -32 & -22 & -12 & -10 \\
\hline $5^{\prime}$ & $\ldots$ & $\ldots$ & $\ldots$ & -4 & -4 & -9 & +5 & +8 \\
\hline $10^{\prime}$ & $\ldots$ & $\ldots$ & $\ldots$ & -2 & -2 & -8 & +8 & +1 \\
\hline $30^{\prime}$ & $\ldots$ & $\ldots$ & $\ldots$ & -10 & +8 & +25 & +4 & +0 \\
\hline
\end{tabular}

We see from schedule VII that the secretion of water depends not only on the concentration of the solution, but more especially on the time the retina stays in the solution. Swelling processes require time, osmotic processes begin quickly and show a quick progress. Thus it can be explained that in the beginning a loss of 
water arises by osmosis, which can be made up for again by the following swelling and can also be surpassed. As the osmotic capacity is well known, it gives a measure of the intensity of the water-binding of the swelling body. In schedule VIII the retina is shown as swelling in saccharose in the same way as in schedule VII.

Schedule Vili.-Saccharose Concentration.

\begin{tabular}{|c|c|c|c|c|c|c|c|c|}
\hline \multicolumn{4}{|c|}{ Time } & $10 \%$ & $20 \%$ & $30 \%$ & $40 \%$ & $50 \%$ \\
\hline $1^{\prime}$ & $\ldots$ & $\ldots$ & $\ldots$ & +13 & +10 & +10 & +5 & -1 \\
\hline $5^{\prime}$ & $\ldots$ & $\ldots$ & $\ldots$ & +5 & +6 & +2 & -8 & -15 \\
\hline $10^{\prime}$ & $\ldots$ & $\ldots$ & $\ldots$ & +0 & +0 & -8 & -9 & -30 \\
\hline $30^{\prime}$ & $\ldots$ & $\ldots$ & $\ldots$ & -5 & -10 & -22 & -35 & -48 \\
\hline
\end{tabular}

If we compare schedule VIII with schedule VII it is evident that these processes occur more regularly in saccharose. In saccharose the influence of concentration and time shows itself very well. This is accounted for by the fact that saccharose only secretes water, whereas pyridin also shows a chemical reaction, which influences the competition between swelling and osmosis in a disturbing way.

Schedules IX and $X$ show the importance of the nature of the swelling and also that the osmotic pressure plays an important rôle. This last fact is demonstrated by the experiments with urea and acetone. These two substances have approximately the same molecular weight whilst the molecular weight of saccharose is about four times greater than that of pyridin.

Schedule IX.-Concentration of UREa.

\begin{tabular}{|c|c|c|c|c|c|c|c|c|}
\hline \multicolumn{4}{|c|}{ Time } & $10 \%$ & $20 \%$ & $30 \%$ & $40 \%$ & $50 \%$ \\
\hline $1^{\prime}$ & $\ldots$ & $\ldots$ & $\ldots$ & -9 & -25 & -29 & -30 & -39 \\
\hline $5^{\prime}$ & $\ldots$ & $\ldots$ & $\ldots$ & +33 & +34 & +26 & -13 & -8 \\
\hline $10^{\prime}$ & $\ldots$ & $\ldots$ & $\ldots$ & +33 & +26 & -5 & -13 & -8 \\
\hline $30^{\prime}$ & $\ldots$ & $\ldots$ & $\ldots$ & +45 & +25 & -5 & -9 & -13 \\
\hline
\end{tabular}

Schedule X.-Acetone-Concentration.

\begin{tabular}{|c|c|c|c|c|c|c|c|c|}
\hline \multicolumn{4}{|c|}{ Time } & $10 \%$ & $20 \%$ & $30 \%$ & $40 \%$ & $50 \%$ \\
\hline $1^{\prime}$ & $\ldots$ & $\ldots$ & $\ldots$ & +15 & +9 & +5 & +3 & +2 \\
\hline $5^{\prime}$ & $\ldots$ & $\ldots$ & $\therefore$ & +60 & +58 & +12 & +13 & +4 \\
\hline $10^{\prime}$ & $\ldots$ & $\ldots$ & $\ldots$ & +20 & +11 & +9 & +8 & +2 \\
\hline $30^{\prime}$ & $\ldots$ & $\ldots$ & $\ldots$ & -12 & -13 & -18 & -18 & -20 \\
\hline
\end{tabular}


It is clearly to be seen from urea experiments that not only no swelling-processes prevail at the first, but that a not unimportant loss of water is found, which is however made up for very quickly and is followed by an even relatively large increase of water. Although a 5 per cent. urea sodium always extracts water out of the retina, even in such strong concentrations fundamentally the same things occur as in weak solutions, as in the time of action the loss of water becomes smaller and smaller. Summarizing we can say that the measuring of the swiftness of the swelling of the retina shows that the retina possesses a not unimportant intensity of water-binding. Yet it is smaller than that of the other tissues of the globe. For a second measurement of the water-binding we have taken the change of density in case of swelling. For this we acted so as to weigh the volume driven out by a piece of the retina. Therefore we used a bottle-pyknometer with a stopper ground in it and capillary tube. We have defined the volume of the pyknometer with water and quicksilver at the prevailing temperature. By doing so the weight of the dry pyknometer was also known to us. After this we first weighed the pyknometer filled with liquid, then the dry pyknometer with the piece of retina and finally the pyknometer with retina and filled with liquid. As a liquid we used xylol, which leaves the retina unchanged within the times of weighing. The specific weight can be calculated from these weighings in the following way :-

Weight of the pyknometer

$\begin{array}{lllllll}\text { Weight of the pyknometer filled } & \ldots & \ldots & \ldots & \ldots & a_{1}\end{array}$

$\begin{array}{lllll}\text { Weight of the } & a_{2}\end{array}$

$\begin{array}{llllll}\text { Weight } & \ldots & \end{array}$

Weight of the pyknometer with retina filled with liquid $\begin{array}{lll}\ldots & a_{3}\end{array}$

In this case is:

$\begin{array}{llllll}\text { The weight } \text { of the piece of retina } & \ldots & \ldots & \ldots & a_{3}-a_{1}\end{array}$

$\begin{array}{llllll}\text { The weight of the liquid } & \ldots & \ldots & \ldots & \ldots & a_{3}-a_{1} \\ \end{array}$

The weight of the liquid minus the weight of the

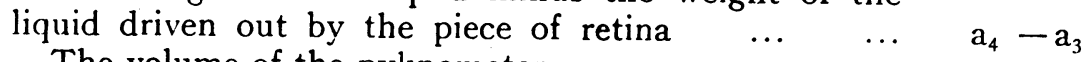

$\begin{array}{llllll}\text { The volume of the pyknometer } & \ldots & \ldots & \ldots & \mathrm{a}_{4} & \mathrm{v}\end{array}$

From this we can calculate the specific weight of the $\begin{array}{lllllllll}\text { liquid (1) } & \ldots & \ldots & \ldots & \ldots & \ldots & \ldots & \ldots & \underline{a_{2}-a_{1}}\end{array}$ and the specific weight of the piece of retina (2) $\frac{\left(a_{3}-a_{1}\right)\left(a_{2}-a_{1}\right)}{v\left(a_{2}-a_{1}-a_{4}+a_{3}\right)}$

In making these measurements, of course, great care must be taken to avoid air bubbles. However xylol penetrated very easily and the pieces of retina were chosen as large as possible. First of all we investigated retina with a normal water-percentage, after 
that pieces which had suffered a definite loss of water by drying in air. The result of the measurements is shown in Fig. 2.

It is evident from this diagram that the specific weight of the retina depends on the water-percentage. A quite dry retina with a water-percentage of zero has a specific weight higher than that

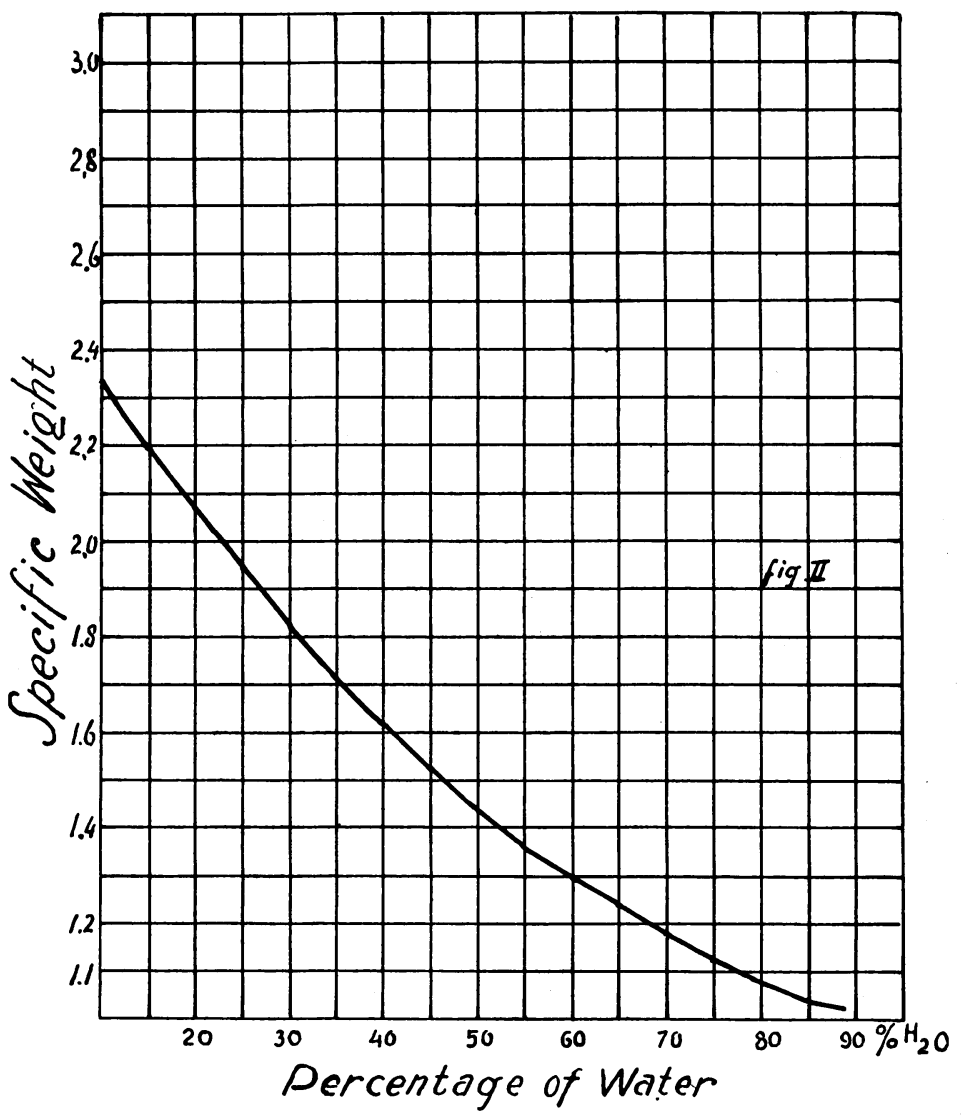

of other tissue of the eye. When the water-percentage increases the specific weight decreases with great regularity. Only the lens shows a similar action. As to the outer walls of the eye the specific weight decreases by leaps and bounds when the water-percentage increases, as to tissues of the uvea we see even an increase. It is a well known fact that swelling gels undergo a contraction of volume or an enlargement of density when in swelling condition, that means that the sum of the absorbed quantity of liquid together with the volume of the dry gel is larger than that of the swollen gel. This contraction of volume is performed very evenly in the retina and in the lens. In the walls by leaps and bounds 
and in the uvea there is no contraction of volume at all at a definite water-percentage, but even a dilatation. We can further conclude from this that in the case of the retina we always see the same way of water-binding. The most probable thing is that the water is always absorbed and retained intramicellarly. This is also the case with the lens as was proved by Hertel, ${ }^{4}$ by the aid of the monochromatic Röntgen method of Debye-Scherrer. Finally we see that by swelling the retina undergoes a relative shrivelling, whereas the uvea swells relatively.

In order to measure the swiftness of the water-secretion we used in the first experimental series acetone solutions of 75 per cent. and 100 per cent. In schedule II the results have been collected. Just as in all other experimental series we measured the loss of water in percentages in these experiments and then afterwards we dried the pieces of retina up to their constant weight in order to get exactly the water-percentage of all the pieces. In this way it was possible to define how firmly and in what way water is bound. The firmness of water-binding, as well as the intensity, can be concluded from the comparison between the capacity to attract water from acetone and the nature of the binding from the fact that according to Wilstätter acetone attracts all the free and capillary-bound water and leaves only the chemically-bound and colloid-bound water behind.

SCHEDUle XI.

\begin{tabular}{|c|c|c|c|c|c|c|c|}
\hline & \multicolumn{3}{|c|}{ Time } & \multicolumn{2}{|c|}{ 75\% Acetone } & \multicolumn{2}{|c|}{$100 \%$ Acetone } \\
\hline & & & & \multicolumn{4}{|c|}{ Water } \\
\hline & & & & Loss & Percentage & Loss & Percentage \\
\hline $1^{\prime}$ & $\ldots$ & $\ldots$ & $\ldots$ & -2 & 88 & -10 & 89 \\
\hline $5^{\prime}$ & $\ldots$ & $\ldots$ & $\ldots$ & -5 & 90 & -54 & 89 \\
\hline $10^{\prime}$ & $\ldots$ & $\ldots$ & $\ldots$ & -16 & 88 & -55 & 87 \\
\hline $30^{\prime}$ & $\ldots$ & $\ldots$ & $\ldots$ & -75 & 89 & -86 & 89 \\
\hline $60^{\prime}$ & $\ldots$ & $\ldots$ & $\ldots$ & -89 & 89 & -89 & 89 \\
\hline
\end{tabular}

It is quite obvious from schedule XI that the retina looses its total water-percentage after 30 minutes in 100 per cent. acetone and after 60 minutes in 75 per cent. acetone. Thus it does not hold its water firmly and the total water-percentage is otherwise than colloido-chemically-bound. This seems to contradict the assertion that the water is intramicellarly bound. We defined 
as colloid-bound water that water which is attached in and round the colloid parts. A micella is a conglomerate of such parts bound by water and in itself also water-binding. There is no doubt that such micellae define indeed the colloid-composition of the retina and consequently we are also sure of a colloid-binding of water. We rather think that the interpretation of the action of acetone is not exact. Acetone removes all "loosely-bound" water, meanwhile its action does not allow of further precision.

That will also do perfectly well for our purpose. The statement that all the water of the retina is but "loosely-bound" is sufficient

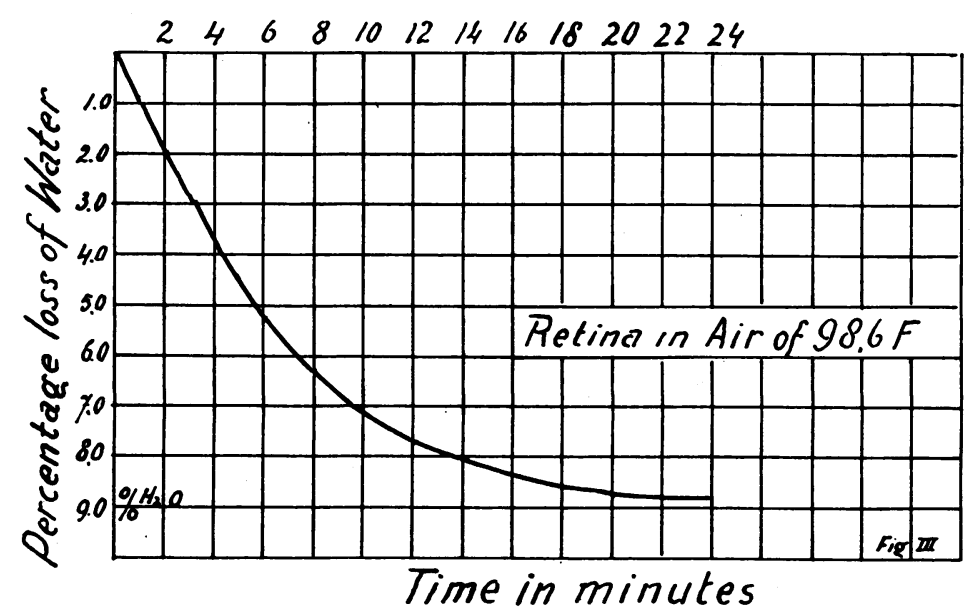

to be able to compare the nature of the water-binding with that of the other tissues of the eye. In no other tissue is all the water loosely bound. In the outer walls only $5 / 6$ of the toral waterpercentage is loosely bound, in the lens about the same amount, only here the time it stays in the liquid must be about 90 times longer in order to remove the quantity of water. Finally we have still to define the swiftness of the water-secretion by measuring the exsiccation-time.

For this purpose pieces of retina which had been weighed were put into thermostats at a temperature of $98.6^{\circ} \mathrm{F}$., they were lying on the perforated basket and all of them were about equally large and equally heavy, and we weighed them each hour until they had their constant weight. The result of these experiments is shown by Fig. 3.

We can see that this water-secretion too makes a very regular progress and that after 20 hours the retina has attained its constant weight. That fact shows a not unimportant intensity of the waterbinding as the walls of the eye get constant after about $1 \frac{1}{2}-2$ hours, 
the tissues of the uvea in 3-5 hours, the nucleus of the lens in 6 hours, and the periphery of the lens only in 19-20 hours. One may say that the duration of the exsiccation-time increases together with the topographical condition of the tissue. The same statement can be made for the intensity of the water-binding, making however one reservation. The measuring of the swiftness of the swelling showed that the same makes slower progress in the retina than in other tissues of the globe, and properly speaking we must conclude from this that the intensity of the water-binding is greater in these tissues. In thinking over this series of experiments, we must come to the conclusion, that the capacity of the water-binding also plays a very important part in these experiments, which excludes the sole function of the intensity. Therefore it is also necessary to make many series of experiments and employ by different methods in order to get a clear insight into this matter. This may also be of importance regarding the understanding of those processes which dominate the water-binding of the vitreous body.

From a clinical point of view we think the result of our experiments worth while for the very reason that it is now an established fact that the retina co-operates in the water-quantity of the eye, and that the alterations of the water movement also affect the retina. The retina reacts upon alterations of the water-percentage of the free water in its neighbourhood, not only in the sense of an oedema, but also by a change of its colloid-structure. Thus it may be altered by very small quantities of such water and also by secretion of water which is certainly specially important. A long time before the changes can be proved pathologically and anatomically the retina shows itself different from that under physiological conditions. We only draw special attention to detachment and glaucoma, which two groups of diseases are certainly able to change excessively the colloid-structure and the waterbinding of the retina.

In connection with this we want to say just one word as to the origin of holes in the retina, for which occurrences a gel-sol conversion must now be seriously considered, the gel-structure of the retina and its change with the water-percentage have been shown.

\section{Summary}

Methods are described by which the water-binding can be defined and it is explained that water-binding, the capacity, the intensity and the nature of the water-binding must be distinguished theoretically and practically. As similar researches had already been carried out for the cornea, the sclera, the uvea and 
the lens, a comparison between the retina and these tissues was possible.

The retina is a swelling gallert with a not unimportant capacity of water-binding. This capacity is much smaller than that of the cornea, sclera, or uvea and larger than that of the lens.

The retina swells in water.

In acids, except in phosphoric acid, the swelling of the retina is checked. This is more marked in concentrated acid, but the action of equinormal acids varies.

Alkalis promote swelling of the retina. This swelling is all the greater in proportion as the alkalis are more concentrated, equinormal alkalis again act variously in strength.

In equally dissociated acids and alkalis the swelling is variable. By salts the swelling of the retina is checked and more strongly in proportion as the salt-solutions are more concentrated.

The action of equimolar salt-solutions is variable.

By anelectrolyte the swelling of the retina is influenced in the same way as by salts.

The rate of swelling of the retina is less than that of any other tissue of the globe.

The change in density in swelling makes very regular progress in the retina and it proves that the retina undergoes a very regular contraction of volume in swelling. Further this is the case only in the lens. Thus the retina undergoes a relative shrivelling in swelling, whereas the uvea, especially the choroid, undergoes a relative swelling.

In the retina all the water is loosely bound, which is not the case in any other tissue of the globe.

The exsiccation-time of the retina is longer than that of all the other tissues of the globe. Regarding the tissues of the eye the exsiccation-time increases going in a direction from the outer walls to the inner parts.

The intensity of the water-binding of the retina is great, greater than its capacity, it is smaller than the intensity of the lens, and greater than that of the other tissues.

REFERENCES.

1. F. P. Fischer.-Arch. f. Augenheilk., Vol. CIII, p. I, 1930; Vol. CVIII, p. 80,1933 .

2. Lange and Simon.-Zeits. f. physiol. Chem., Vol. CXX, p. 1, 1922.

3. Hofmeister. - Arch. f. exper. Path., Vol. XXII, p. 395, 1890; Vol XXVII, p. 210, 1891.

4. Hertel.-A rch. f. A ugenheilk., Vol. CVII, p. 259, 1933. 